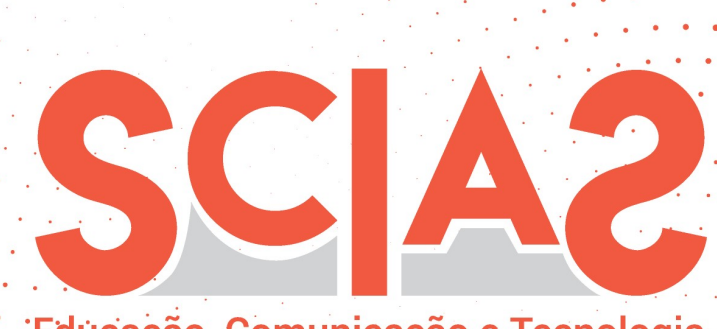

Educuçaçã̉o, Comunicação e Tecnologia

Atribuiçãa BB CY 4.0

\title{
Um caminho não imaginado: mães cientistas em debate com a ordem do discurso
}

Luciana Gomes da Luz Silva ${ }^{1}$

\section{Resumo}

O presente trabalho pretende apresentar um panorama de como a pandemia alterou a lógica de funcionamento das relações de mães cientistas com seus filhos, trabalho, escola e estudos. Historicamente, a localização física do ambiente de trabalho e de escola, foi organizada para existir em espaços diferenciados e bem delimitados geograficamente. Essa configuração se modificou drasticamente no contexto pandêmico impondo que a realização das tarefas profissionais e escolares passasse a existir nas próprias casas. Somado a essa alteração, o uso da tecnologia passou a ser central na vida de todos independente da existência de críticas anteriores a essas ferramentas. Observase ainda, o atravessamento de questões ligadas a gênero e raça nesse contexto.

\section{Palavras-chave}

Maternidade. Pandemia. Tecnologia.

Recebido em: 13/o8/2020

Aprovado em: 26/01/2021

\footnotetext{
${ }^{1}$ Graduada em Psicologia pela UFMG (1997). É especialista em Democracia pela UFMG (2008). Atualmente é servidora Técnico-Administrativo em Educação da UFMG e mestranda do Programa de Pós-Graduação: Mestrado Profissional, Educação e Docência da linha de Ensino e Humanidades.

E-mail: lucianaluz158@gmail.com
} 


\title{
An improbable path: scientific mothers in debate with the order of discourse
}

\begin{abstract}
The present article intends to present an overview of how the pandemic has altered the logic of functioning of the relations of scientific mothers with their children, work, school and studies. Historically, the physical location of the work and school environment has been organized to exist in different and welldefined geographic spaces. This configuration has changed drastically in the pandemic context, imposing that professional and school tasks should be carried out in their own homes. In addition to this change, the use of technology has become central to everyone's life regardless of the existence of previous criticisms of these tools. It is also observed, the crossing of issues related to gender and race in this context.
\end{abstract}

\section{Keywords}

Maternity. Pandemic. Technology. 


\section{Introdução}

Ficar em casa em isolamento social é uma missão quase impossível para mulheres negras. Em sua grande maioria elas se inserem nas atividades ditas essenciais e estão na linha de frente de combate à pandemia, geralmente na condição de técnicas de enfermagem, faxineiras ou ainda, o mais comum, como domésticas cuidando das casas e dos filhos de seus empregadores. As imagens apresentadas nos meios de comunicação nas quais se observa pessoas confinadas em seus apartamentos luxuosos, ansiosas pelo retorno à vida 'normal' estão distantes da realidade daquelas que vivem nas periferias e precisam sair de suas casas ou pseudo-casas, mesmo correndo riscos de se contaminarem com o novo coronavírus para garantir o próprio sustento e o de seus familiares.

Pra mim, ser mulher negra, cientista e mãe vivendo em isolamento social, nesse período de pandemia, tem sido um privilégio diante da consciência de que esta experiência não é compartilhada pela grande maioria da população negra. Reconheço que ultrapassei uma das barreiras de desigualdade que me permitiu viver de fato essa quarentena. É sabido que o racismo estrutural nega acessos às pessoas unicamente por possuírem em seus corpos traços negroides que são desvalorizados socialmente. Vencer essa dura realidade só foi possível com muita resistência e resiliência (ALMEIDA, 2019).

Em González (1984) observamos que o lugar das pessoas pretas está bem definido na sociedade e localiza homens pretos como malandros e ladrões e as mulheres negras surgem no imaginário como cozinheiras, faxineiras, prostitutas. Aqueles e aquelas que fazem a travessia para uma vida diferente dessa, em determinados contextos são considerados como não pretos, ou seja, são branqueados. Por isso é comum a expressão 'preto de alma branca', imersa no racismo, essa frase representa o pensamento de que cabe somente aos brancos acessar uma educação de qualidade e assim garantir uma especialização adequada que os habilite a trabalhos mais valorizados (GONZÁLES, 1984). 
Sabemos, no entanto, que a qualificação não é suficiente para que pessoas pretas tenham acesso. Tal realidade somente será possível a partir do debate quase que diário acerca das questões étnico-raciais que possam mobilizar o maior número de pessoas em prol dessa causa.

Na perspectiva de Quilomba (2019) a mulher negra não é nem homem, nem mulher, ela é o outro do outro, ou seja, habita um vazio e está à margem das questões de raça, pois não é homem negro e também está de fora das questões de gênero, pois não é mulher branca. Como se a função da mulher negra fosse ser esse outro do outro.

Em Carneiro (2019) temos uma crítica ao movimento feminista que desconsiderou as mulheres negras ao levantarem pautas que desconsideravam as suas realidades. Além disso, as mulheres brancas não questionaram o padrão estético de beleza atribuído a elas, já que obviamente segue a branquitude. Às mulheres negras não se aplica o título de rainhas do lar, uma vez que não são rainhas de nada e são anti-musas. Assim também temos que o mito da fragilidade feminina não se aplica às mulheres negras que sempre estiveram no mundo do trabalho na condição de escravas, ou mesmo, após o período da escravidão, assumindo funções de vendedoras, quituteiras e prostitutas.

Nesse sentido é possível inferir que a produtividade das mulheres negras, mães e cientistas sofreu pouco impacto com as mudanças advindas da pandemia, uma vez que mulheres negras estão habituadas a dobrar/triplicar suas jornadas de trabalho. E, além disso, estão habituadas a dar mais de si em qualquer situação pandêmica ou não. Característica imposta às mulheres negras que se esforçam mais para provarem suas próprias capacidades.

\section{A maternagem em tempos de pandemia}

Percebo que a maternagem está em evidência nesse período de isolamento social. Mães que jamais imaginaram passar tanto tempo com os filhos em razão do excesso de trabalho fora de casa estão experimentando essa possibilidade. A rotina pesada de trabalho antes dessa quarentena impedia que as mães 
acompanhassem de perto o aprendizado dos filhos e com isso pudessem criar laços mais afetivos na vida escolar dos filhos.

Vale notar que até para algumas crianças, a vida fora de casa era uma realidade presente em suas histórias já que tinham um número alto de atividades extraclasse promovido pelos pais com o intuito de buscar uma formação mais próxima do mercado de trabalho já desde a tenra idade. Nas classes populares também é possível para algumas crianças passar um longo tempo fora de suas casas na medida em podiam participar de projetos sociais ou escola integrada.

Esse novo contexto familiar de convivência em tempo integral, a meu ver tem aproximado mães e filhos/as que têm uns aos outros para vivenciar todas as horas de dia, já que estamos impossibilitados de sair. Obviamente esse convívio intenso faz emergir novas relações afetivas atravessadas por bons e maus momentos. Todo e qualquer conflito será vivenciado no mesmo espaço físico. Importa buscar maneiras de contornar as turbulências com coerência e assertividade.

Observo naqueles que estão confinados no mesmo espaço, o desejo de continuar a vivenciar essa experiência, ainda que tanto tempo já tenha se passado. Para estas famílias, estar juntos é mais importante do que substituir o contato por redes sociais. A interação tem sido corpo a corpo e os afetos perpassam as relações. A impossibilidade de sair impede a não resolução dos conflitos surgidos. Por sorte, não existe o recurso de fugir pra longe e evitar as negociações. Entendo como positiva essa experiência desde que ancorada no respeito à dignidade dos envolvidos.

Vale ponderar que a idealização da maternidade remonta ao período da modernidade quando a mulher passou a ser considerada essencial para os cuidados dos próprios filhos, tarefa atribuída anteriormente a amas-de-leite ou escravas. É a partir da constituição da família nuclear que surge a ideia dessa mãe protetora cuja função principal será a exclusividade da criação de seus filhos (STELLIN et.al, 2011). 
Argumentamos que a mulher considerada na literatura exemplifica a que está categorizada na racialidade dominante, ou seja, a branca. Nas classes subalternas as mulheres negras permanecem na invisibilidade contribuindo para a manutenção destas famílias nucleares, na execução de serviços domésticos. Ou seja, a idealização da maternidade como identificado pela autora supracitada, de alguma forma já era vivenciada por essas mulheres que sempre cuidaram de seus filhos e dos filhos dos outros. E assim, será possível observar que além manter suas funções na execução das tarefas da casa, eventualmente, ainda assumirão a posição de mãe-preta, cuidando dos filhos das patroas (GONZÁLEZ, 1984).

Importante registrar o estudo de Stellin et al (2011) que apontou as direções que levam à construção do ser mãe, como um processo que inicia-se na gestação e vai sendo construído minuciosamente em etapas. Nesse processo os sentimentos vividos pelas mulheres interferem nessa maternagem. A pesquisa mostrou como a recepção do pai interfere no processo seja pela aceitação ou rejeição tanto da criança quanto da própria mãe da criança. A experiência com a figura paterna terá efeito na construção da relação dessa mulher com o bebê, e consequentemente, o reflexo disso no surgimento dessa mãe. Fatores externos quer sejam financeiros, sociais, familiares e até políticos também impactam essa construção materna. Nesse aspecto podemos afirmar que uma mulher não se configura primordialmente como mãe, a função materna é um processo de construção, ou seja, fundamentalmente efeito de uma operação psíquica (STELLIN et al, 2011, p.4).

Acredito que para além dos cuidados iniciais com os filhos a construção do ser mãe é um processo contínuo que requer muito investimento psíquico. Nesse período de pandemia onde as incertezas tomam o lugar das certezas, as crianças contam com a mãe para auxiliá-los, e esperam nelas alguma garantia para seguirem em frente. Essa experiência íntima das mães com seus filhos transcende as questões relativas ao contexto social experimentado. Trata-se de uma realização singular pertinente a cada experiência de maternagem. 
Vale registrar que as angústias advindas do medo que ora circular em razão da Covid-19 afetam as crianças de várias maneiras. Outro dia ouvi uma criança dizendo que estava com muito medo de andar na rua por causa do 'covid'. A percepção das crianças varia muito, de acordo com a sua fase do desenvolvimento. Elas podem imaginar ou fantasiar sobre a doença a partir daí. No tocante às mães entendemos que elas se transformam em porto seguro no qual as crianças se sentirão amparadas. Nestas experiências vivenciadas no território familiar, as ideologias de poder atravessadas por conceitos raciais se dissolvem e autorizam mulheres negras ou não, a exercerem a própria maternagem.

Outro aspecto fundamental é que mesmo sendo fruto de uma construção social surgida para preservar o patrimônio, a imagem da mãe protetora e amorosa, propiciará às crianças nesses tempos pandêmicos alguma organização mental. $\mathrm{E}$ ao considerar essa tônica é importante enfatizar que uma mulher não se configura primordialmente como mãe, a função materna é um processo de construção, ou seja, fundamentalmente efeito de uma operação psíquica (STELLIN et al, 2011, p.4).

Nessa perspectiva acreditamos que para suportar esse momento, nós mulheres cientistas e mães também precisaram cuidar de nós mesmas. Para isso, poder contar com redes de apoio é fundamental para que possamos subsidiar a nossa própria sobrevivência. $\mathrm{Na}$ rede de apoio o suporte oferecido por familiares promove suporte emocional tanto para as mães quanto para as crianças. Importante avaliar o momento onde pode ser necessário contar com apoio profissional para mães e filhos. Esse suporte possibilitará a travessia nesse momento tão atípico em nossas vidas (DESSEN; BRAZ, 2000).

\section{Um novo jeito de existir durante o isolamento}

A imposição do isolamento social tem possibilitado um olhar pra dentro de si e apresentado reflexões sobre o sentido das oportunidades e de como ressignificar as vivências. Até antes da pandemia, um dos grandes conflitos administrados pelas mães dizia respeito ao uso constante do celular pelos filhos. Estratégias 
sobre oferecer ou não esse aparelho aos filhos e qual a idade mais indicada para fazerem uso desse instrumento, suscitavam imensos debates nas escolas, sociedade e famílias. De repente, no momento da pandemia, esse instrumento passou a ser fundamental tanto para o trabalho remoto dos pais quanto para as aulas online dos filhos.

Arrisco-me a considerar que essa proposição remete à reflexão acerca do discurso encontrada em Foucault (2002):

Trata-se de determinar as condições do seu funcionamento, de impor aos indivíduos que os pronunciam um certo número de regras e assim não permitir, que todo mundo tenha acesso a eles. Rarefação, desta vez, dos sujeitos que falam; ninguém entrará na ordem do discurso se não satisfizer certas exigências, ou se não for, de início, qualificado para fazê-lo. Mais precisamente: nem todas as regiões do discurso são igualmente abertas e penetráveis; algumas são altamente proibidas (diferenciadas e diferenciantes), enquanto outras parecem quase abertas a todos os ventos e postas sem restrição prévia, à disposição de cada sujeito que fala. (FOUCAULT, 2012, p.3637)

E assim, o discurso proferido anteriormente conflitua com a nova realidade e passa a ser proferido por indivíduos que não estavam autorizados ou qualificados para fazerem, ou seja, as mães passam a ditar novas regras familiares alteradas em razão da pandemia que impactaram um espaço do saber que acontecia em território distinto do ambiente doméstico. Da mesma forma, essas mães repactuaram suas próprias relações de trabalho e de estudo, no caso, das cientistas, pois esses territórios também adentraram o espaço da casa.

Ensejava-se pela delimitação bem definida de espaços físicos para realização das atividades ligadas ao trabalho e aos estudos. Tais espaços localizavam-se preferencialmente em contextos geograficamente diferenciados do espaço do lar. No entanto, vivenciamos uma ruptura por força da pandemia, ou seja, os discursos acerca da definição de locais apropriados para o exercício de cada atividade, considerados como verdade e reconhecidos como a fórmula mais adequada àquela situação, tornaram-se 'invalidados', mesmo que momentaneamente. Espera-se que ao final do processo pandêmico, a regularidade das interações sociais que ocorriam nesses ambientes retorne, uma 
vez que há muitas perdas em decorrência da falta de socialização acarretada pelo isolamento social.

A experiência atual remete à reflexão acerca do papel da educação e as novas relações a serem estabelecidas diante de tantas incertezas. Mas ainda assim mantém-se como o lócus de disseminação das lógicas relacionais:

[...]a educação, embora seja, de direito, o instrumento graças ao qual todo o indivíduo, em uma sociedade como a nossa, pode ter acesso a qualquer tipo de discurso; segue, em sua distribuição, no que permite e no que impede, as linhas que são marcadas pela distância, pelas oposições e lutas sociais. Todo o sistema de educação é uma maneira política de manter ou de modificar a apropriação dos discursos, com os saberes e os poderes que eles trazem consigo. (FOUCAULT, 2012, p. 44-45)

Consoante a todas as indagações acerca do uso de tecnologias conjugadas à educação, ainda insipientes de estudos conclusivos sobre a sua aplicabilidade ao ensino formal, foi preciso incluir essa nova abordagem de estudos na rotina das instituições que diante das urgências, passou adotar o discurso de que somente dessa forma seria possível manter os estudos, ou seja, essa era a única opção encontrada para continuidade das formações escolares. Junto com a adoção desse novo sistema de ensino, no caso remoto emergencial, somou-se uma gama de críticas e dúvidas sobre a eficácia de seu uso e abrangência, no sentido de ter acessibilidade para todos os estudantes. E assim, os saberes e os poderes implícitos nos discursos seguem presentes nas novas dinâmicas de estudos. Alguns serão excluídos enquanto que aqueles ligados à esfera do poder continuaram mantendo os status quo.

Importante registrar que apesar de todos os esforços para tentar garantir um retorno às aulas que permita a volta de todos, pensamento idealizado por movimentos sociais e dirigido aos gestores, para os demais que se encontravam em condições de se adequar à nova realidade, restou a reorganização da vida de forma a experimentar novas lógicas de pensamento e de ações. Para a outra parcela, alheia a essa realidade por questões imperiosamente econômicas, coube um esforço maior de adequação ou simplesmente desistir de tentar. 
A situação de pandemia evidenciou que as verdades estão em constante devir e que novas construções estão na base das relações. Grande parte desse recorte de mudanças está ancorado nos sujeitos demandantes que exigem novas configurações para o próprio existir:

O discurso nada mais é do que a reverberação de uma verdade nascendo diante dos seus próprios olhos; e quando tudo pode, enfim, tomar a forma do discurso, quando tudo pode ser dito e o discurso pode ser dito a propósito de tudo, isso se dá porque todas as coisas tendo manifestado e intercambiado o seu sentido, podem voltar à interioridade silenciosa da consciência de si. (FOUCAULT, 2012, p.48-49)

As ações empreendidas por coletivos que buscam o reconhecimento de suas pautas indicam o nascimento dessas novas verdades requeridas por sujeitos alijados de direitos. Cabe o destaque para os movimentos de representatividade como o feminista, negro, lgbt que buscam ampliar a consciência da sociedade acerca de suas existências e a conseqüência de sua invisibilidade no tocante a acessos. Assim, a partir dessa perspectiva, a educação teria que problematizar o contemporâneo jogo duplo de inclusão-exclusão, para o qual as redes sociais servem, ao questionar seus interesses e mensurar o grau de exposição de seus usuários (MION; CARVALHO, 2020, p. 32).

Observamos que ainda, que além de promover e até mesmo antecipar o uso do celular pelos filhos, algo tão polêmico antes de todo esse processo pandêmico, é preciso também dominar a ferramenta de modo a conseguir acessar os conteúdos das aulas e as várias plataformas de contato online. E ainda controlar o acesso cuidando para que as crianças não acessem conteúdos inadequados ou sejam expostas a perigos na rede.

Importante fazer a ressalva de que além dos cuidados específicos ligados à saúde ditados pela pandemia, deve-se atentar para o cuidado com o uso das tecnologias. A adoção de estratégias capazes de proteger dos riscos desse ambiente virtual faz-se extremamente necessária:

Essas estratégias possibilitam que os envolvidos desenvolvam uma postura mais cética quantos aos conteúdos disponibilizados, e fomentam assim o surgimento de um sujeito mais ético, pois, para além de uma postura individualista, com intuito de apenas sanar seus desejos materiais de consumo, o 
sujeito pode também estabelecer uma relação mais respeitosa para com o outro. (MION; CARVALHO, 2020, p. 34)

O domínio da tecnologia em tão pouco tempo não é uma tarefa simples, sobretudo, pra quem se virava no básico. Se antes para compreender o uso desse instrumental fazia-se necessário acessar algum curso específico, na atualidade diante da urgência, recorre-se à própria internet para entender como usá-la. Há vários canais que fornecem orientações básicas para acessar minimamente a maioria dos recursos.

De outro lado, a necessidade de ampliar o uso da internet permitiu acessar uma fonte enorme de informações que possuem ligação direta à pesquisa que vem sendo produzida. A quantidade de 'lives' com a temática estudada produzidas em plataformas como Instagram, YouTube, Facebook, Twitter, dentre outros, me possibilitou acessar pessoas e grupos de pesquisa, que da maneira tradicional, seria impossível acompanhar. Vale lembrar que muitos desses processos eram conduzidos na forma de seminários presenciais em diferentes localidades que necessitavam de um investimento financeiro seja para inscrição no evento, seja para possibilitar as viagens e hospedagens quando necessário. Agora basta navegar pela internet e descobrir várias possibilidades de aprendizagem.

Junto com a necessidade de dominar as novas ferramentas de trabalho, pesquisa e estudos dos filhos, ficou evidenciado que para o uso adequado desses instrumentos se faz necessário ainda que os equipamentos tenham uma qualidade melhor e que a internet, em si, seja capaz de possibilitar o acesso, com qualidade de transmissão que favoreça o aproveitamento da atividade a ser desenvolvida.

A partir da exigência de equipamentos possíveis para acessar recursos de aulas online e internet suficiente para acessar conteúdos de trabalho, estudo e pesquisa, percebemos que o próximo caminho a ser incorporado pela pandemia é o estabelecimento de novos consumidores de tecnologia desenvolvidos nesse contexto. E assim o mundo capitalista vence ao conseguir impor a sua aposta de envolver as crianças no universo do consumo: 
Aposta-se assim em cativar os públicos cada vez mais precocemente, opta-se por "catequizar" os consumidores cada vez mais cedo, ainda em sua tenra idade, para obter um mercado estendido e longevo, ao ponto de as crianças serem os alvos preferidos dos discursos envolventes do mercado que os perseguem pela vida adulta até chegarem ao túmulo. (MION; CARVALHO, 2020, p. 26)

Compete aos responsáveis cumprir esse novo ritual de consumidores de tecnologia, situação imposta pela atualidade para que seja incorporado o acesso a um bem eletrônico. Talvez para aquele grupo de pessoas esta aquisição jamais se faria caso o contexto fosse outro, seja por considerá-lo inadequado pra idade dos filhos ou por que a necessidade de uso se limitava ao espaço do trabalho, enfim, ainda pior que isso, tal instrumento poderia não ser adquirido por questões meramente econômicas. Ao incorporar esse novo discurso, quer seja, adquirir equipamentos eletrônicos modernos, adequar a rede de internet da casa, aplica-se aos responsáveis das crianças transmitir que a mudança de foco, ocorreu em razão das urgências advindas do momento atual. Possivelmente a maioria dessas crianças estava sempre a solicitar acesso ilimitado às novas tecnologias, assim, diante da disponibilização de uso autorizada e incentivada pelas famílias, corre-se o risco de causar incertezas e confusão na mente dos pequenos.

Diante desses apontamentos evidencia-se que no contexto em questão, o trabalho remoto em isolamento social, o andamento da pesquisa e o ensino das crianças, de fato, sobrecarregou as mães. Soma-se a isso a intensificação do trabalho doméstico que foi ampliado em razão da impossibilidade de compartilhá-lo. Para quem podia contar com esse suporte foi recomendado o afastamento dos profissionais do lar. Lembrando que também que realizar refeições fora de casa saiu da rotina durante a quarentena. Nesse cenário, a mães foram presenteadas com a urgência em se especializarem em tecnologias mesmo que não a dominem. Dar sequência à pesquisa sem o suporte de uma biblioteca física e de um local exclusivo para os estudos. Ser professora de nossos filhos e filhas mesmo que jamais tenhamos cursado licenciatura ou desejado ter essa profissão.

Vale a reflexão acerca da fluidez dos processos educacionais: 
a educação nos tempos líquidos não pode mais ser focada em uma ordem social imutável, sólida e com perspectiva de longa duração, e sim deve se preparar para adquirir novos significados diante das atuais circunstâncias sociais, conferindo a ela o mesmo tratamento dos outros temas, como consumo, relações pessoais e éticas, assumindo assim uma perspectiva crítica. . (MION; CARVALHO, 2020, p. 32)

A mudança das relações familiares de forma tão abrupta provocou novos desafios. É no contexto das casas que todas as vivências acontecerão. Será nesse espaço antes tão íntimo e destinado a momentos de relaxamento que tensões escolares, de trabalho e as provenientes do contexto familiar, propriamente dito, ocorrerão. Não há como fugir. As interações só poderão ocorrer nesse local. É com a mãe que a criança dividirá a experiência da aula e é com o filho que mãe fará os desabafos do mundo do trabalho e também da pesquisa. Saíram de cena os colegas de sala de aula, de trabalho. Os universos ficaram mesclados fisicamente e emocionalmente no mesmo ambiente e também. As mães conheceram mais a fundo os/as professoras dos filhos e estes conhecerão as chefias e seus modos de agir. Outras janelas também se abrirão nessas relações: nas chamadas 'lives', acontecimento presente na ordem do dia, será possível a todos que por elas estão em interação, conhecer um pedacinho da casa de cada um, tornando as relações ainda que mediadas por uma tela mais intimistas.

\section{Considerações finnais}

A experiência do isolamento social diz de uma excepcionalidade na vida de todos nós. Ninguém poderia imaginar estar confinado em casa impedido de sair pelo risco de contrair uma doença desconhecida, sem remédio ou vacina. A cada dia que passa o grupo de risco deixa ser o grupo mais frágil e pessoas aparentemente seguras se tornam vítimas fatais.

Por tudo isso, a insegurança impera afetando nossos sentimentos e nos deixando ansiosos à espera de um milagre como a notícia da tão esperada cura. E diante dessa exceção como lidar com as expectativas das crianças diante de tantos sonhos que jamais serão realizados este ano? Como seguir sem saber se o sacrifício está valendo a pena? 
Nós pesquisadoras seguimos acreditando que a pesquisa terá sua utilidade e que seus resultados terão o impacto desejado no início de tudo. Mesmo com novos desafios como a realização de todo o processo no espaço de casa sujeito às intercorrências do ambiente doméstico. Vale registrar que nem todas têm conseguido se manter firmes no propósito dos estudos. As intempéries dos novos tempos causaram um sofrimento mais intenso que acarretou na interrupção temporária do processo. Mas de um modo geral as atividades tem sido encaminhadas.

Seguir com a restrição do espaço e acesso a informações externas tem sido um grande desafio para a continuidade das pesquisas. Mas ao mesmo tempo, trabalhar nessa nova perspectiva se apresenta também como novidade que merece ser testada.

O cuidado com os filhos demonstra o quão necessária se faz a presença das mães nesse contexto pandêmico para que eles também possam seguir suas rotinas. No momento, o normal é o que estamos vivendo e as crianças precisam se sentir seguras e acreditar que o que estão fazendo fará sentido.

Haverá um momento em que as tecnologias deixarão de ser o único contato com o mundo externo e a vida seguirá mais leve. Os contatos físicos voltarão a existir e o mundo dos abraços voltará a existir.

Mas até lá valerá essa realidade confinada em que o único espaço de interação é o da própria casa. E vale também a nostalgia de lembrar que não fosse a pandemia não teria acontecido a experiência de passar tanto tempo juntos aprendendo novos processos de convivência. Conhecendo as particularidades de cada um nos momentos felizes e de stress.

Vale lembrar que o aprendizado principal diz da importância de se manter cuidados básicos de saúde com vistas ao cuidado global de todos. Importante acreditar que não esqueceremos essa experiência. Mesmo que venha a vacina da cura, novas experiências pandêmicas poderão acontecer. Seria bom manter certos hábitos que foram aprendidos nesses tempos. 
Acredito ainda que a oportunidade de conexão com as pessoas mais próximas, forçada por esse contexto, possa se traduzir em novas formas de se relacionar. Até mesmo pessoas distantes estão se reconectando através do uso da tecnologia para recuperar amizades.

As relações familiares seguirão novos rumos. As certezas acerca de tudo ruíram. Não é possível planejar com garantia sobre o que poderá ser experimentado nos próximos dias. A doença invisível mostrou que é preciso parar e refletir sobre novas formas de viver que considerem que mudanças são suscetíveis de acontece a qualquer instante e que é preciso estar preparado pra elas.

\section{Bibliografia}

ALMEIDA, S. L. Racismo estrutural. São Paulo: Pólen Livros, 2019.

DESSEN, M. A.; BRAZ, M. P. Rede social de apoio durante transições familiares do nascimento de filhos. Psic .: Teor. e Pesq. , Brasília, v. 16, n. 3, p. 221-231, dezembro de 2000. Disponível em: <http://www.scielo.br/scielo.php?script=sci_arttext\&pid=S010237722000000300005\&lng=en\&nrm=iso >. Acesso em 30 de julho de 2020.

CARNEIRO, S. Escritos de uma vida. São Paulo: Pólen Livros, 2019

GONZÁLEZ, L. Racismo e sexismo na cultura brasileira. In: Revista Ciências Sociais Hoje, Anpocs, 1984, p. 223-244. Disponível em: $<$ https://edisciplinas.usp.br/pluginfile.php/4584956/mod resource/content/1 /06\%20-\%20GONZALES\%2C\%20L\%C3\%Aglia\%20-

\%20Racismo e Sexismo na Cultura Brasileira\%20\%281\%29.pdf >. Acesso em 11 ago. 2020

FOUCAULT, M. A ordem do discurso: aula inaugural no Collège de France, pronunciada em 2 de dezembro de 1970. Tradução de Laura Fraga de Almeida Sampaio. São Paulo: Edições Loyola, 2012.

MION, M.; CARVALHO, M. J. Educação em tempos de redes em uma sociedade de consumidores. SCIAS Educação, Comunicação e Tecnologia. v. 2, n. 23, p. 23-38, jan-jun, 2020. Disponível em: <http://revista.uemg.br/index.php/SCIASEdcomtec/article/view/4458/2765>. Acesso em 11 ago. 2020

QUILOMBA, G. Memórias da Plantação: Episódios de racismo cotidiano. Rio de Janeiro: Cobogó, 2019. 
STELlin, R. et al . Processos de construção de maternagem. Feminilidade e maternagem: recursos psíquicos para o exercício da maternagem em suas singularidades. Estilos da clinica, São Paulo, v. 16, n. 1, p. 170-185, jun. 2011 . Disponível em:

sic.bvsalud.org/scielo.php?script=sci_arttext\&pid $=\mathrm{S} 1415^{-}$

71282011000100010\&lng=pt\&nrm=iso >. Acesso em 11 ago. 2020. 